\title{
ANALISIS DAN DESAIN SISTEM INFORMASI PENGOLAHAN NILAI SISWA DI SMK AVICENA RAJEG
}

\author{
Desty Dwi Pertiwi ${ }^{1}$, Rohmat Taufiq ${ }^{2}$ \\ ${ }^{1,2}$ Jurusan Teknik Informatika, Fakultas Teknik, Universitas Muhammadiyah, Tangerang \\ J1. Perintis Kemerdekaan I/33 Cikokol, Kota Tangerang, 15118, Indonesia \\ email: ${ }^{1}$ desty1297@gmail.com; ${ }^{2}$ rohmat.taufiq@umt.ac.id
}

\begin{abstract}
Abstrak
Perkembangan teknologi informasi sekarang semakin berkembang pesat di segala bidang sehingga banyak perusahaan dan instansi-instansi terus berusaha meningkatkan pengolahan data yang lebih efektif dan efisien guna menunjang produktifitas kerja. Di SMK Avicena Rajeg pengolahan nilai masih menggunakan Microsoft Excel dan belum menggunakan aplikasi khusus. Menganalisa sistem informasi pengolahan nilai pada SMK Avicena Rajeg merupakan sarana untuk menunjang kinerja para wali kelas dan guru. Metode yang digunakan penulis meliputi metode wawancara, metode observasi, metode kepustakaan dan Unified Modeling Language (UML) untuk mendeskripsikan model sistem yang berjalan dan sistem usulan. Berdasarkan permasalahan yang ada, hasil dari pembahasaan pengolahan data nilai siswa belum dilihat secara online sedangkan fasilitas jaringan komputer sudah cukup baik. Penulis menyarankan perlu dilakukan evaluasi secara berkala, dibuatnya sebuah sistem dengan menggunakan bahasa pemrograman PHP dan server database MySql, agar data terjamin keamanannya serta meminimalisir kesalahan dalam pendataan.
\end{abstract}

Kata Kunci - Sistem Informasi, Pengolahan data nilai, Microsoft Excel, UML.

\section{Abstract}

The development of information technology is now growing rapidly in all fields so that many companies and agencies continue to strive to improve data processing more effectively and efficiently to support work productivity. At SMK Avicena Rajeg, value processing still uses Microsoft Excel and has not used a special application. Analyzing the value-processing information system at the Avicena Rajeg Vocational School is a means to support the performance of homeroom teachers and teachers. The method used by the writer includes interview method, observation method, library method and Unified Modeling Language (UML) to describe the running system model and the proposed system. Based on the existing problems, the results of the discussion of student data processing have not been seen online while the computer network facilities are good enough. The author suggests that periodic evaluations be made, a system is created using the PHP programming language and MySql database server, so that data is guaranteed to be safe and minimize errors in data collection.

Keyword: Information systems, Value data processing, Microsoft Excel, UML

\section{PENDAHULUAN}

Perkembangan teknologi informasi sekarang semakin berkembang pesat di segala bidang sehingga banyak perusahaan dan instansi-instansi terus berusaha meningkatkan pengolahan data yang lebih efektif dan efisien guna menunjang produktifitas kerja. Manfaat dari perkembangan teknologi informasi yang sangat penting adalah penggunaan alat pengolah data yang berfungsi menghasilkan informasi yang dibutuhkan secara cepat, akurat, relevan, serta tepat sasaran. Perusahaan ataupun instansi yang akan maju dan sukses harus mengikuti era informasi dengan menggunakan pendukung pengolah data yaitu komputer.

Sistem informasi merupakan sekumpulan sistemsistem yang saling terintregasi satu sama lain untuk menghasilkan suatu informasi yang dapat berguna bagi pemakainya. Dengan sistem informasi maka data dan informasi akan tersimpan dalam suatu database sistem sehingga data menjadi teratur serta memudahkan pemakai apabila membutuhkan data tersebut. Oleh karena itu hampir semua kalangan instansi saat ini memanfaatkan sistem termasuk juga dalam dunia pendidikan.

Seiring kemajuan ilmu pengetahuan dan teknologi saat ini, kini komputer digunakan di perusahaan, instansi dan sekolahan. Digunakan dalam berbagai bidang menjadi lebih baik, cepat dan efisien. Dalam kegiatan pendidikan pun diperlukan adanya suatu sistem komputerisasi dalam berbagai keperluan. Khususnya dalam pengolahan nilai siswa di sebuah Sekolah Menengah Kejuruan (SMK).

Di SMK Avicena Rajeg, komputer telah diperkenalkan dan dipergunakan untuk pembelajaran praktek bagi siswa-siswi dan pekerjaan dibidang akademik. Dalam dunia pendidikan, komputer berguna untuk memudahkan dalam pelayanan untuk siswa dan wali kelas ataupun orang tua siswa. Dalam hal ini, 
pengolahan nilai masih menggunakan Microsoft Excel dan belum menggunakan aplikasi khusus. Upaya dalam pengolahan data dan informasi akan berhasil dengan perubahan yang lebih baik pada sistem yang ada (Microsotft Excel). Sehingga apabila terjadi kesalahan dan keterlambatan saat perhitungan pengolahan nilai yang banyak menyita waktu dan membutuhkan banyak tenaga dapat diperkecil.

Untuk itu, penulis mengamati sistem nilai siswa agar kemudahan, kecepatan, dan ketepatan dalam pengolahan nilai siswa dapat terlaksana sehingga diharapkan dapat membawa kemajuan dalam pelayanan nilai Siswa. Berdasarkan uraian di atas maka penulis tertarik untuk membahas Laporan Kuliah Kerja Praktek ini dengan judul "Analisis Sistem Informasi Pengolahan Nilai Siswa Pada SMK Avicena Rajeg".

\section{TINJAUAN PUSTAKA}

\section{A. Pengertian Analisis Sistem}

Menurut Taufiq (2013) sistem adalah kumpulan dari sub-sub sistem baik abstrak maupun fisik yang saling terintegrasi dan berkolaborasi untuk mencapai suatu tujuan tertentu sedangakn informasi adalah data-data yang diolah sehingga memiliki nilai tambah dan bermanfaat bagi pengguna [4].

"Sistem informasi adalah kumpulan dari sub-sub sistem yang saling terintegrasi dan berkolaborasi untuk menyelesaikan masalah tertentu dengan cara mengolah data sehingga memiliki nilai tambah dan bermanfaat bagi pengguna (Taufiq, 2018) [5]. Sebuah sistem inofrmasi berbasis komputer sudah di teliti dan dirancang yang memiliki manfaat mempermudah perusahaan dalam melakukan pengarsipan surat masuk dan surat keluar pada cv. Sumber Karya Teknik (Desi, dkk 2019) [2]

B. Pengertian Pengolahan Nilai

"Pengolahan nilai siswa merupakan salah satu bagian dari kegiatan belajar mengajar (KBM) di sekolah, yang sangat berperan penting dalam belajar mengajar yang merupakan alat ukur prestasi siswa. Dengan adanya pengolahan dan manajemen yang baik pengolahan data nilai akan lebih mudah, cepat, dan akurat."'[3].

C. Pengertian UML

Unified Modeling Language (UML) adalah salah satu standar bahasa yang banyak digunakan di dunia industri untuk mendefinisikan requirement, membuat analisis dan desain, serta menggambarkan arsitektur dalam pemrograman berorientasi objek. UML merupakan bahasa visual untuk pemodelan dan komunikasi mengenai sebuah sistem dengan menggunakan diagram dan teks-teks pendukung.

UML hanya berfungsi untuk melakukan pemodelan. Jadi penggunaan UML tidak terbatas pada metodologi tertentu, meskipun pada kenyataannya UML paling banyak digunakan pada metodologi berorientasi objek (Rosa A.S dan M. Shalahudin, 2014) [1].

\section{METODE PENELITIAN}

\section{A. Objek Penelitian}

Penulis melakukan penelitian pada SMK Avicena Rajeg untuk mengetahui bagaimana sistem yang berjalan pada proses pengolahan nilai siswa dan memenuhi tugas kerja praktek dari Prodi Teknik Informatika, Universitas Muhammadiyah Tangerang.

Dari hasil pengamatan penulis selama melaksanakan kerja praktek, penulis mendapati bahwa pengolahan nilai siswa masih bersifat manual. Proses pengolahan rapor siswa diawali dengan guru mata pelajaran memberikan nilai pengetahuan dan nilai keterampilan di file Microsoft Excel serta memberikan deskripsi nilai secara manual.

Setiap data yang didapatkan oleh wali kelas mempunyai format yang berbeda, tergantung dari guru yang menyerahkan. Tidak semua guru mampu menggunakan komputer dengan baik sehingga terdapat perbedaan dalam penyerahan nilai ke wali kelas.

Prosesnya dimulai dari penyusunan format leger nilai untuk guru dan leger rapor untuk wali dalam bentuk softcopy file spreadsheet oleh Bagian Evaluasi. Lalu Bagian Evaluasi mengunggahnya ke server jaringan komputer lokal SMK Avicena Rajeg yang nantinya dapat diunduh oleh semua guru. Guru mengisi nilai yang berdasarkan format yang dibuat Bagian Evaluasi. Kemudian guru mengunggahnya kembali ke email. Setelah itu wali kelas mengunduh hasil nilai yang telah diunggah guru, untuk dimasukkan ke dalam leger rapor. Setelah semua nilai masuk ke leger rapor, wali kelas akan mencetak rapor.

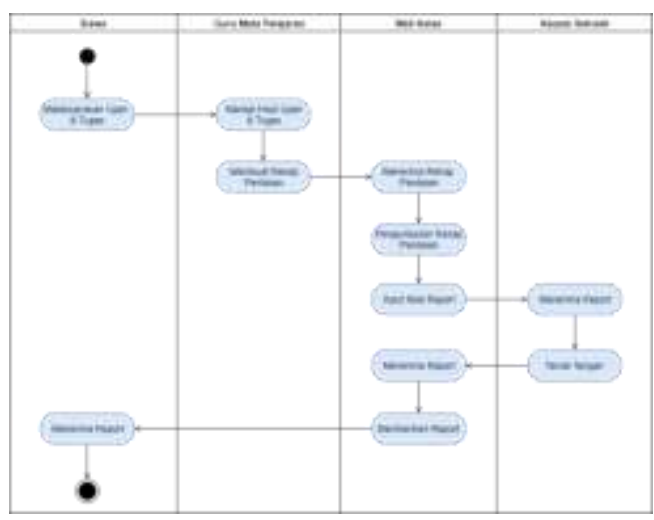

Gambar 1 Activity Diagram Sistem Yang Sedang

Berjalan

Alur aktifitas yang digambarkan pada Activity Diagram diatas adalah :

- Prosesnya dimulai dari Siswa melaksanakan Ujian dan Tugas yang sudah diberikan.

- Lalu guru mata pelajaran menilai hasil ujian dan 
tugas, kemudian membuat rekap penilaian dan memberikan rekap nilai kepada wali kelas.

- Wali kelas menerima rekap penilaian dan mengumpulkan nilai yang didapat dari masingmasing guru mata pelajaran, kemudian menginput nilai raport dan memberikan kepada Kepala Sekolah untuk di tanda tangani.

- Kepala sekolah menandatangani raport yang diberikan oleh wali kelas dan mengembalikannya kembali ke wali kelas.

- Setelah wali kelas menerima raport yang sudah di tanda tangani, wali kelas memberikan raport kepada siswa sesuai dengan jadwal pembagian raport.

\section{B. Masalah Yang Dihadapi}

- Dengan pengolahan nilai yang masih menggunakan Microsoft Excel mengakibatkan sering terjadi salah input dan data yang sama.

- Nilai raport belum bisa di lihat secara online oleh orang tua.

\section{Alternatif Pemecahan Masalah}

Setelah mengamati dan meneliti dari beberapa permasalahan yang terjadi pada sistem yang berjalan, penulis mengusulkan beberapa alternatif pemecahan dari permasalahan yang dihadapi, antara lain:

- Perlu dilakukan evaluasi secara berkala terhadap prosedur pengolahan nilai.

- Perlu dibuatnya sebuah sistem yang dapat membantu dalam membantu dalam pengolahan data nilai sehingga dapat mempercepat proses pelayanan terhadap sekolah, misalnya dengan menggunakan bahasa pemrograman PHP dan server database MySql, agar data terjamin keamanannya serta meminimalisir kesalahan dalam pendataan.

- Dengan analisa dan perancangan yang di jelaskan dalam bab sebelumnya, penulis berharap dapat menjadi acuan sekolah dalam membuat sistem.

\section{HASIL DAN PEMBAHASAN}

\section{A. Usulan Prosedur Yang Baru}

Setelah menganalisis sistem yang berjalan pada SMK Avicena Rajeg Kabupaten Tangerang, terdapat beberapa kekurangan dalam proses pengolahan nilai siswa terutama dalam proses pencatatan dan pembuatan laporan. Maka selanjutnya akan dibahas mengenai rancangan usulan sistem yang akan dibangun.

Rancangan prosedur yang diusulkan bertujuan untuk menyempurnakan dan memberikan alternatif dalam memberikan informasi juga mempermudah Guru dan Wali Kelas dalam penginputan data nilai secara terkomputerisasi, memudahkan siswa atau orang tua dalam mengecek pengolahan nilai yang dapat dilihat secara online, serta memudahkan Kepala Sekolah dalam meriview laporan.
Perbedaan sistem yang berjalan dengan sistem yang disusulkan semoga akan memberikan dampak positif bagi pihak yang menggunakannya, supaya dalam pelaksanaan pengolahan nilai bisa lebih efektif dan efesien. Adapun perancangan sistem yang coba diusulkan ini dibuat dengan menggunakan $U M L$.

\section{B. Diagram Rancangan Sistem}

Rancangan sistem ini adalah tahapan perancangan sistem yang akan dibentuk yang dapat berupa penggambaran proses-proses suatu elemen-elemen dari suatu komponen. Proses perancangan ini merupakan suatu tahapan awal dari perancangan aplikasi dari sistem pengolahan nilai.

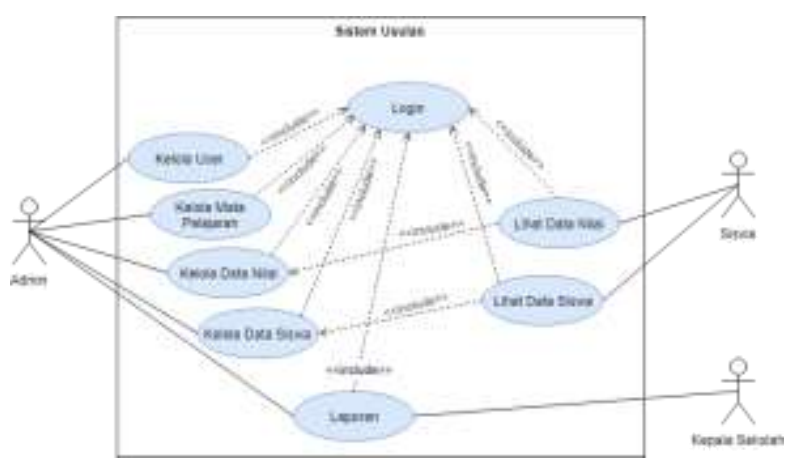

Gambar 2 Usecase Diagram Sistem yang diusulkan

Pada Gambar 2 Usecacase Diagram, ada beberapa actor yang terlibat dalam sistem. Diantaranya adalah Admin, Siswa dan Kepala Sekolah.

Tabel 1 Penjelasan Aktor Usecase Diagram

\begin{tabular}{|c|c|c|}
\hline No & Actors & Penjelasan \\
\hline 1 & Admin & $\begin{array}{l}\text { Admin yaitu orang yang } \\
\text { melakukan pengololahan data, } \\
\text { kelola user untuk di approve } \\
\text { sebelum login, kelola data } \\
\text { siswa, kelola data nilai dan } \\
\text { mencetak. }\end{array}$ \\
\hline 2 & Siswa & $\begin{array}{l}\text { Siswa yang dapat login adalah } \\
\text { siswa yang sudah mempunyai } \\
\text { akun, yang di berikan oleh } \\
\text { admin sekolah, siswa dapat } \\
\text { melihat data diri dan data } \\
\text { nilai. }\end{array}$ \\
\hline 3 & $\begin{array}{l}\text { Kepala } \\
\text { Sekolah }\end{array}$ & $\begin{array}{l}\text { Mendapatkan hak akses untuk } \\
\text { me-review laporan pengolahan } \\
\text { nilai siswa. }\end{array}$ \\
\hline
\end{tabular}


Pada Gambar 3-8 yaitu Statechart Diagram dan Activity Diagram yang digunakan untuk menggambarkan proses alur sistem yang diusulkan untuk SMK Avicena Rajeg. Diagram ini mengandung aktifitas dari masing-masing usecase pada Usecase Diagram yang diusulkan.Gambar Statechart Diagram dan Activity Diagram pada jurnal ini hanya beberapa saja, gambar lengkap dari diagram terdapat dalam laporan kerja praktek.

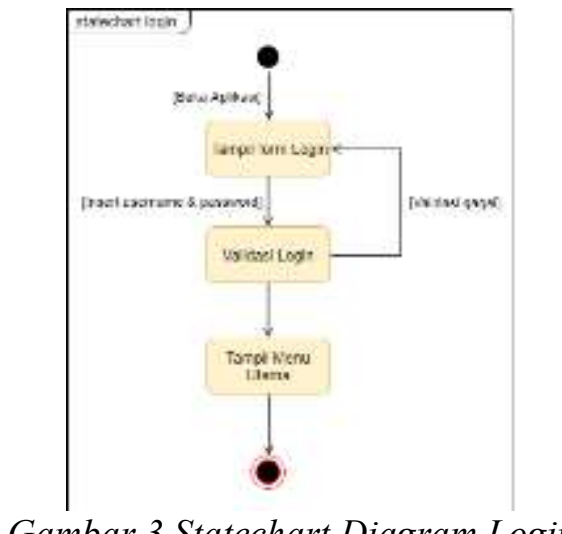

Gambar 3 Statechart Diagram Login

Deskripsi Gambar 3. Tampilan login akan muncul jika user masuk ke website terlebih dahulu dan ingin melakukan login sistem. User harus menginput username beserta password (untuk admin) dan NIS beserta password (untuk siswa)jika ingin masuk ke sistem sesuai hak akses masing-masing.

Setelah user menginput maka sistem akan melakukan validasi. Jika sesuai maka sistem akan menampilkan menu utama sesuai hak akses masing-masing. Dan jika validasi gagal maka sistem akan kembali menampilkan tampilan login beserta pesan kesalahan.

Dalam tampilan utama setelah login untuk admin, sistem akan menampilkan halaman utama pengolahan nilai berisi menu kelola user, kelola mata pelajaran, kelola data siswa,kelola data nilai, laporan.

Sedangkan untuk siswa atau orang tua, sistem akan menampilkan halaman utama lihat data nilai, lihat data siswa, ubah password, logout.

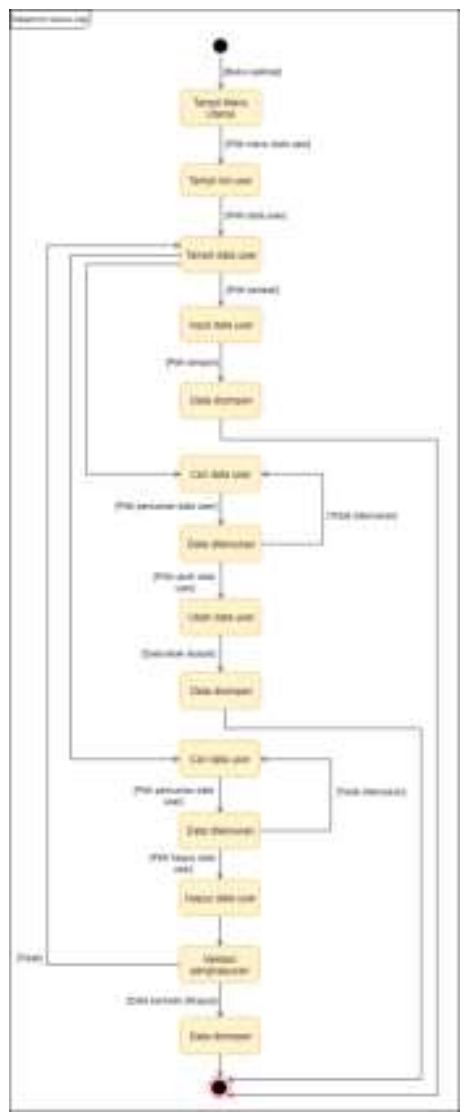

Gambar 4 Statechart Diagram Kelola User

Deskripsi Gambar 4. Tampilan menu kelola user akan muncul jika admin berhasil masuk ke website setelah menginput username beserta password.

Dalam menu kelola user, admin dapat menambahkan data user baru untuk melihat nilai yang dilakukan oleh siswa. Dan melakukan pencarian data untuk proses ubah data atau hapus data user.

Proses dari kelola user sendiri cukup panjang karena adanya CRUD (Create, Read, Updateand Update) yang merupakan dasar dari suatu pengelolaan.Penjelasan dari CRUD pada Activity Diagram kelola user adalah sebagai berikut:

- Create berarti admin bisa menambahkan data user baru.

- Read berarti admin bisa mengecek data dari user dengan melakukan pencarian data terlebih dahulu.

- Update berarti admin bisa melakukan perubahan data pada data user yang diiinginkan dengan melakukan pencarian data terlebih dahulu.

- Delete berarti admin bisa menghapus data user yang diinginkan dengan melakukan pencarian data terlebih dahulu- 


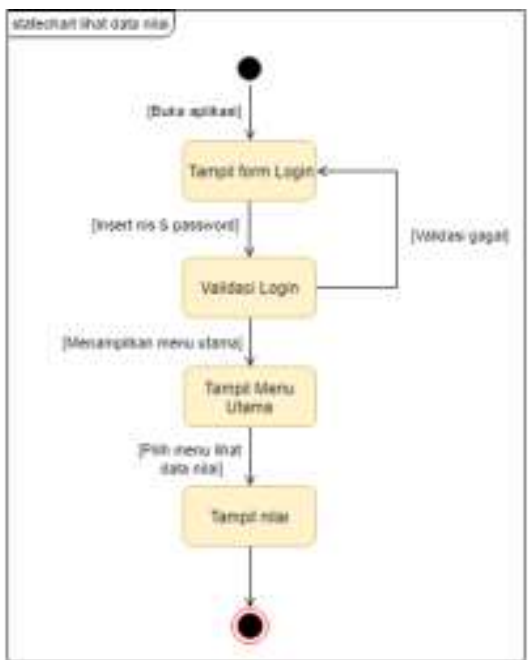

Gambar 5 Statechart Diagram Lihat Data Nilai

Deskripsi Gambar 5. Tampilan menu lihat nilai akan muncul jika siswa berhasil masuk ke website setelah menginput username beserta password.

Dalam menu lihat nilai, siswa harus terlebih dulu masuk ke website pengolahan nilai. Setelah itu sistem akan menampilkan menu utama. Lalu siswa akan memilih menu lihat data nilai.

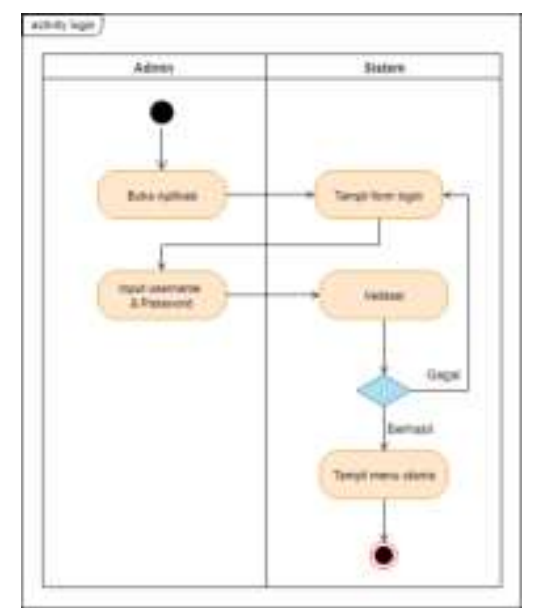

Gambar 6 Activity Diagram Login

Deskripsi untuk Gambar 6 sama dengan deskripsi dari Gambar 3

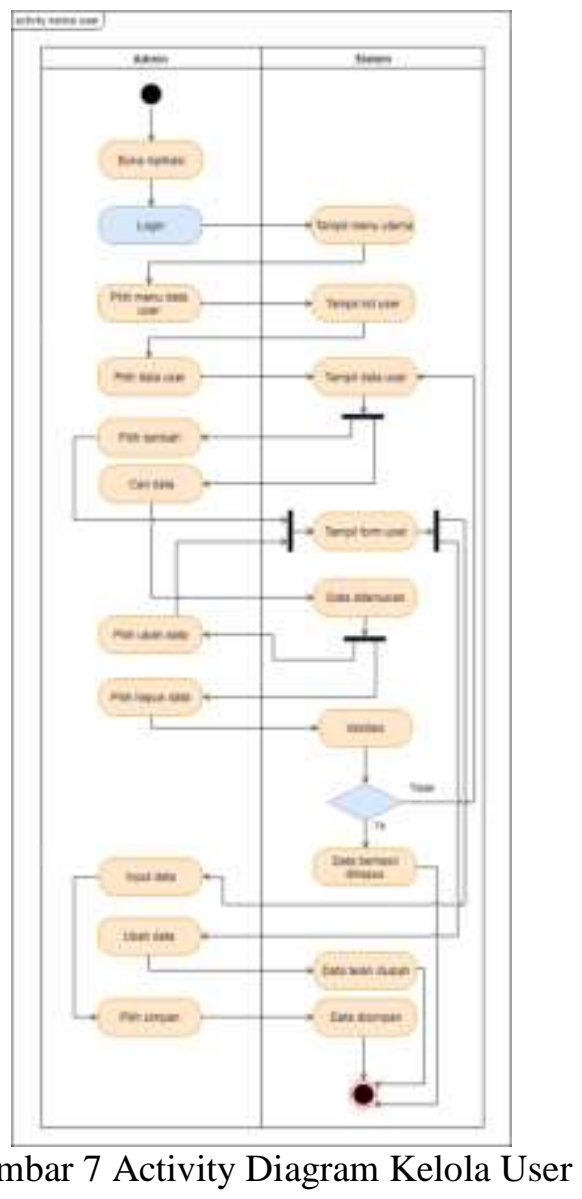

Deskripsi untuk Gambar 7sama dengan deskripsi dari Gambar 4

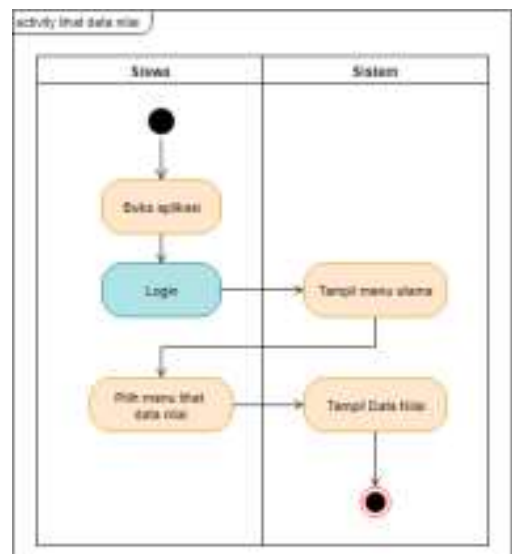

Gambar 8 Activity Diagram Lihat Nilai

Deskripsi untuk Gambar 8sama dengan deskripsi dari Gambar 5

C. Rancangan Desain Antarmuka

Pada rancangan desain antarmukaakan dibagi menjadi dua, yakni sistem pengolahan nilai untuk Guru dan Wali Kelas dan Lihat Nilai dan Lihat Data Siswa untuk siswa. 


\section{Desain Antarmuka Sistem Pengolahan Nilai}

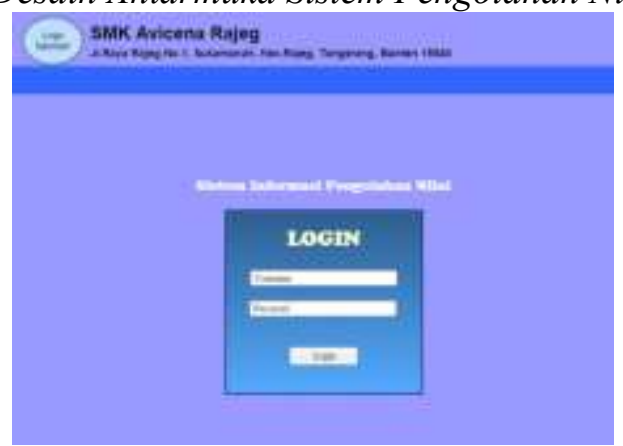

Gambar 9 Desain Antarmuka Sistem Login

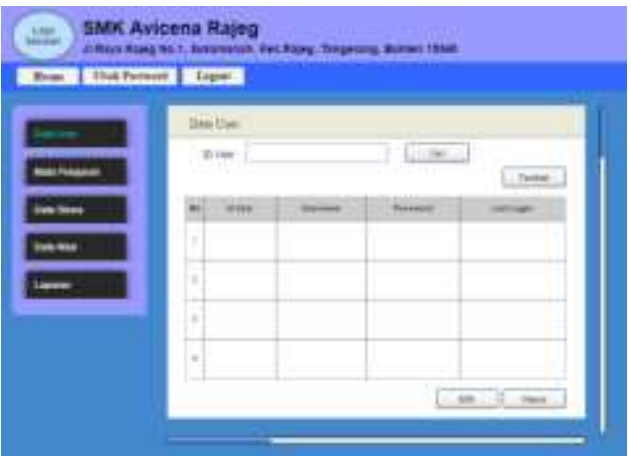

Gambar 10 Desain Antarmuka Menu Data User

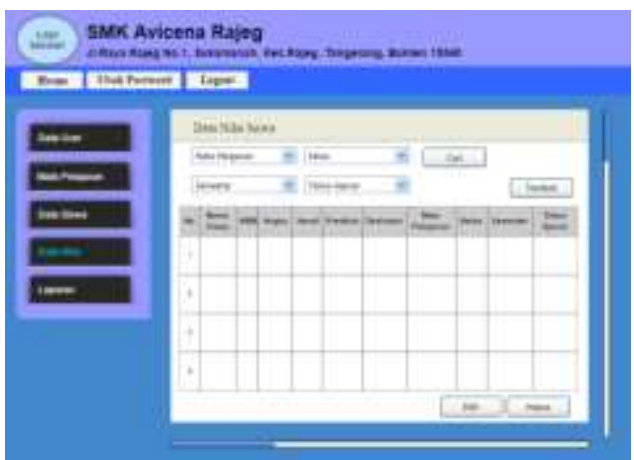

Gambar 11 Desain Antarmuka Menu Pengolahan Nilai

2. Desain Antarmuka Sistem Lihat Nilai Siswa

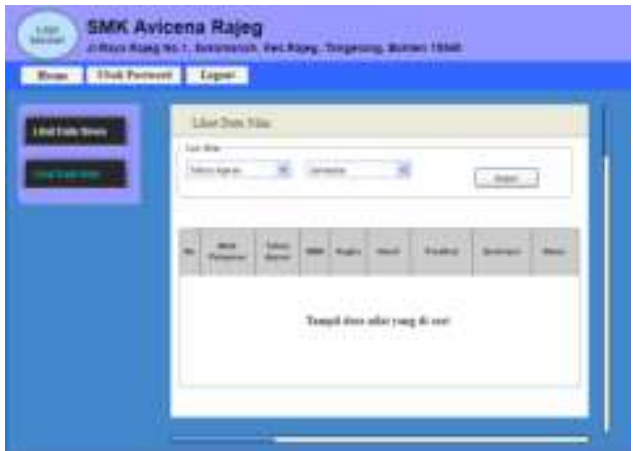

Gambar 12 Desain Antarmuka Menu Lihat Nilai

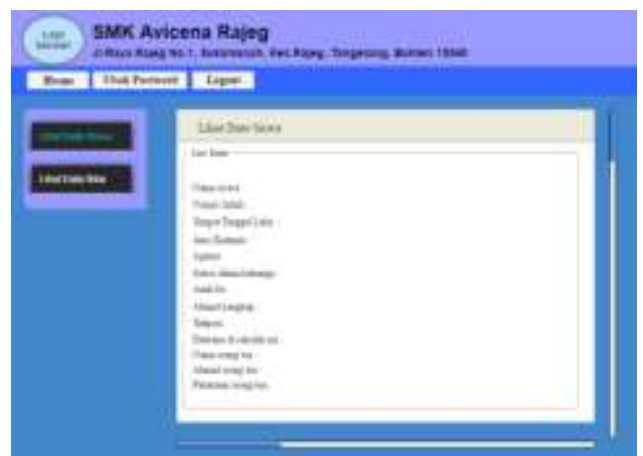

Gambar 13 Desain Antarmukam Menu Lihat Data Siswa

\section{KESIMPULAN}

Berdasarkan hasil penelitian yang dilakukan pada sistem pengolahan nilai siswa SMK Avicena Rajeg, maka dapat disimpulkan sebagai berikut:

- Sistem pengolahan nilai siswa yang berjalan saat ini di SMK Avicena Rajeg masih menggunakan Microsoft Excel dan belum menggunakan aplikasi khusus. Sehingga apabila terjadi kesalahan dan keterlambatan saat perhitungan pengolahan nilai yang banyak menyita waktu dan membutuhkan banyak tenaga. Serta sering terjadi salah input dan data yang sama. Dan nilai siswa belum bisa dilihat secara online untuk siswa dan orang tua.

- Pada pembahasan yang sudah dipaparkan sebelumnya, perancangan dari sistem informasi pengolahan nilai pada SMK Avicena Rajeg memudahkan Guru dan Wali Kelas dalam melakukan proses pengolahan nilai siswa serta memudahkan Guru atau Wali Kelas maupun Kepala Sekolah untuk me-review laporan pengolahan nilai. Selain itu, siswa dan orang tua juga dapat melihat pengolahan nilai secara online.

\section{DAFTAR PUSTAKA}

A. S Rosa dan M. Shalahuddin. 2014. Rekayasa Perangkat Lunak Struktur dan Berorientasi Objek. Bandung: Informatika.

Nurnaningsih. D, Destriana. R dan Mubaroq D. S. 2019. Rancang Bangun Sistem Informasi Pengarsipan Surat Masuk dan Keluar Studi kasus pada CV. Sumber Karya Teknik. Jurnal Teknik Informatika (JIKA).ISSN: 2519-0710

Permana, A. A. (2016). Rancangan Sistem Informasi Simpan Pinjam Pada Koperasi Guru dan Pegawai SMP Negeri 45 Jakarta. JIKA (Jurnal Informatika) Vol. 1 No.2 2017 ISSN 2549-0710. 
Sinta, Istiatul, "Perancangan Sistem Informasi Pengolahan Data Nilai Siswa Pada Sd Negeri 164 Pekanbaru" Jurnal Intra-Tech Vol. 2, No.2, Oktober 2018 ISSN. 2549-0222

Taufiq, Rohmat. 2013. “Sistem Informasi Manajemen: Konsep Dasar, Analisis dan Metode Pengembangan". Yogyakarta: Graha Ilmu.

Taufiq, Rohmat. 2018. "Pengantar Sistem Informasi". Jakarta. Mitra Wacana Media. 